\title{
Research on the safety value and use value
}

\author{
Wei Liu ${ }^{1}$, Chenyu Liu², Xiaohong Chen ${ }^{3}$ \\ ${ }^{1}$ School of management, North China Institute of Science and Technology, Beijing, China \\ ${ }^{2}$ School of Economics and Management, Chongqing University of Posts and \\ Telecommunications, Chongqing, China \\ ${ }^{3}$ China mines safety report, North China Institute of Science and Technology, Beijing, China
}

\begin{abstract}
KEYWORD: Value; Safety value; Safety Use Value; Labor Safety; Production of Duality
ABSTRACT: Authors of papers to proceedings from two dimensions, namely Marx labor value, value and use value are be discussed for the dimensions of the safety philosophy thinking, analysis that the safety "production" is the unity of the use value and the use value. This has theoretical and practical significance for the enterprise to further improve the safety of the "production". This article aims at changing the business' ideology that the enterprise is just the production of a product or service concept of economics, the enterprise's production has the dual nature, one is that the enterprise is safety's production system, that is, the safety investment, namely human, financial, and material input, ensure the enterprise is a safety system; second is that the enterprise is the product or service of the production system, that is, the production investment, namely human, financial, and material input, ensure the enterprise is a product or service production system. Sometimes it is a unified process, sometimes requiring the separation of the two, but the ultimate unity. The function of the second system can be played only when the first system is effective. To admit that the safety value, be helpful for dealing with social contradictions related to the safety accidents, and safety value become the important basis of safety investment.
\end{abstract}

\section{INTRODUCTION}

Upholding and developing Marx's labor theory of value, you must insist on scientific development ideas and methods, so as to apply the Marxist theory in the new field, value and use value in the field of new problems. Clearing the connotation of the concept of labor value, applicable conditions and scope is the premise and foundation deep understanding of Marx's labor theory of value, which is also a deep understanding the basis of the safety management connotation and safety professional division of labor.

\section{MARX'S LABOR THEORY OF VALUE AND THE VALUE OF SAFETY}

Marx's labor value theory mainly has the following aspects:

First, the value is the category of social relations rather than the entity category or attribute category of object itself. Marx clearly objected to the value of the property as an absolute thing or the crops [1]. To become something absolute, the attribute of a thing, instead of regard him as something relatively as the social relations of material and labor, as the basis of social labor relations of matter and in a private exchange, in this kind of social labor, rather than separate things, but as social production performance is required [2]. Marx emphasized value is different from the use value of another relative social existence, illustrates the theory of labor value to the dependence of content as the foundation, in the exchange as the medium of social, how to implement the universal social material exchange, comprehensive, the relationship between various needs, and comprehensive ability system of the problem [3]. This reveals that under what interests or relations of production can make the private labor become social work, and this has no relationship with the characteristics of individual labor. Whether in the private labor or social production, that paying to the workers compensation is the remuneration to hire the labor, which is in order to obtain the product of labor, resulting in a compensation payment for the goods. That is to say, simply assumed that there are no accidents 
harm laborers cases, but the production of safety is the important relationship between employees and employers, because accident will destroy the employment relationship or employment relationship. So the safety has the social attribute.

Second, the value is reflected in the social work, rather than the specific labor or private labor. Value must be realized through the exchange of commodities to achieve the transfer of private labor to social labor. Labor exchange and labor socialization are the essence of value. As the exchange of goods, the product is the labor exchange and the certain form of the labor's dependence on the other person's labor. It is a certain way of social labor or social production [4]. Safety work is the premise and foundation in the production of products, safety work is in order to obtain safety products (can be invisible), the safety products are be produced before the production, production and after production must exist, it also is an important part of social necessary labor, which shall be consumption by producers, and spending by consumers. In other words, producer in labor process, two kinds of benefits, one is safety income, namely through their production safety or others for production safety, including safety investment in enterprises) to obtain the body and mind from accident of income, the other one is to obtain payment for labor to maintain health. Therefore, safe labor has value.

Third, the value is a measure of social labor, which is a form of wealth, and productivity development level. Wealth is the sum of natural objects inherent and human labor to create all use value, and the value is a measure of the social labor in the form of a scale, but this form with fewer human necessary labor cost, natural productivity and social productivity greatly become meaningless, after all, to withdraw from the stage of history [1]. With the development of large industrial, real wealth creation, less depending upon the labor time and labor consumption, mainly depends on the used in the work time of power, and this kind of motivation itself - their huge efficiency - is the amount of direct labor time and produce them out of proportion, on the contrary, depends on the general level of science and technology progress, or depends on scientific application in production [4]. Safety value is recessive, only through whether safety investment or not contrast display, such as no safety investment, enterprise high probability of the accident, accidents caused by the stagnation of production, production decline, and accident caused personal injury and equipment damage to the facility and environmental damage, these negative effects can the safety input, namely, the production safety to resolve, safety can be to ensure normal production smoothly, eliminates the output decline and reduce the loss of the accident, which is can be used to measure value, this is the life value of safety. Fourth, Value is a kind of social contradiction in commodity society, and also the essential medium and effective means to solve the contradiction. The relationship between private labor and social labor, specific labor and abstract labor in the production of goods is the intrinsic source of the value. The formation of the general equivalent, that value from the concept form to the independent monetary form, to solve the social contradiction provides the necessary intermediary and effective means. The value of the commodity is determined by the average of the society. The average social average labor time is only one kind of theoretical abstract, in fact it is the product of the product of the commodity producer under the different production conditions. The social production conditions of different commodity producers are never the same in fact and remain in constant change. The labor consumption of the same commodity is different, which indicates that production conditions, technical conditions, labor experience and labor intensity are different. Producers can only do everything possible to reduce the individual necessary labor time, and the real exchange of goods is not at a loss or profit [4]. safety in the Production safety is also in the production of social contradictions and the relationship between human and nature between the contradictions, the safety needs of safety investment, which requires human labor, and the labor cost to calculated and compensated, so it has value. The recognition of the safety has the value, is conducive to dealing with the social contradictions of the accident, the safe value of the important basis for safe investment.

Fifth, Classical economics labor theory of value is out of the labor theory of value, which is a special form, so didn't understand the workers' wages, profits, capital essence, cannot explain the surplus value to the law of value of abnormal or deviation [5]. It is only in the understanding of the value of 
labor, we can deeply understand the use value and the value difference for the scientific understanding of the significance of commodity value, in order to get rid of use value for the value of entangled. The foothold and starting point of Marx's labor value theory analysis is to illustrate the commodity's value and use value is different, only to distinguish the commodity's use value and value, and to distinguish labor's use value and value in the labor force commodity [4]. The two are the conditions and the premise of each other. The problem of the value of labor is the breakthrough point and breakthrough point of Marx's critique and development of labor value theory. The productions of safety have the attribute of labor value and the attribute of commodity value.

\section{SAFETY PRODUCTION VALUE AND USE VALUE}

\section{The production of safety has the use value}

The use value of the commodity is the attribute that can satisfy people a certain need; it is the natural attribute of article. It is one of the basic attributes of commodity, the material of value, and the material content of forming social wealth. Use value is one of the common attributes of all commodities. Any goods to become goods must have the value of the value of human use; conversely, the goods without the value of the goods will not become a commodity. The use of value is created by the specific labor, and has the quality of the non - comparison. The use value is the material basis of value and value, together, constitute the dual character of commodity. Safe production can meet the producer's safe utility, that is, no accident, no casualties, equipment damage, environmental pollution, production pause. The complexity of modern production technology, making the use of the value of safety is also created by the specific labor, and thus has the use value; safe production is the use value and value of unity.

\section{The production of safety has value}

The use value of the first to reflect the things for human survival and development of a positive role, and to push the theoretical value in the natural sciences, it must be first solved using unified value measurement. The standard of assessing the value of things is called the value judgment standard. Such as the subjective consciousness, desire, emotion and emotion and other factors as the standard of assessing the value of things, as the subjective value judgment standard, it is the subjective reflection of the objective value criteria. According to the biggest nature law of the unified value theory shows: the fundamental purpose of the human subject is to maximize the development of their nature, the key to the measure of all things for human subject of the size value is to see that the things to maintain and develop the essential force of human body generated by the impact. From this, the objective criterion of value judgment is that the objective standard of the value of the subject is the essence of the subject. The greatest function of the safety of production is to maintain and maintain the productive forces, or to maintain the normal production of enterprise capacity, with an indispensable value.

\section{Safe production is the unity of the value and the use value}

For individuals, it is personal labor ability that judge things for personal use value, depends on whether the thing is conducive to the maintenance and development of personal labor ability. For the collective, it means the collective productive force, which is social productive force. Use value can be classified as a means of subsistence use value and production data use value, each class respectively, the needle against different human subject, and service to different objective. Therefore, it is different evaluation criteria. Among them, the life of information service in the process of personal consumption, the use value is to labor as the evaluation standard; production data is service in the production process of the collective, the use value is to collective productivity for objective evaluation criteria.

\section{The use value of the life data contains the use of safety}

The value of life data is only for individuals, to maintain and develop the individual's labor ability. According to the unified theory of value, means of subsistence use value first through the consumption process of transformation for potential labor, again in the labor process transformation for labor 
value, which constitutes a person's ability to work, it to labor the influence degree depends on labor potential generation quantity, namely living data use value depending on it in people's consumption in the process of the transformation of labor potential. The human labor potential can be divided into four basic levels: Food and clothing, health and safety, self-esteem and human dignity, self development and self -realization. Among them, dress warmly and ear one's fill labor potential standard available foods contain biological chemical energy performance; a class of labor potential can be converted into a certain number of former labor potential. Therefore, all types of labor potential can be converted into a certain number of food and clothing to the labor potential, such as safety can be reduced to the kind of food and clothing, so all types of living data use value can be converted into a certain number of standard food energy.

From this obtain that the use value of life depends on the degree of the consumption of individual labor power and the equivalent of the standard food energy. The value of the measurement of the use value of production: the use value of the production depends on the value amount of life used in the course of production in the process of depreciation. The safety products and services are the major categories of the production data. Therefore, the use value of it's depends on the amount of the life data that is transferred in the course of production in the way of depreciation. It can be seen that the health and safety is following the food and clothing, followed by the emergence of the labor potential, it is in the process of consumption, make the individual in safe state, to maintain and develop the individual's ability to work, or ensuring that individuals in safe condition for consumption, to ensure that the process of consumption can be safely transformed to the labor potential of, and then in the labor process smoothly transformation for labor value, smooth constitute a person's ability to work. It can be seen that the use value of life information contains the use value of safety.

\section{Components of safe using value}

The value of safe use includes: function value, dissipation value, using value. Specifically:

(a)Functional value: the effect of all the positive factors inside the object is the functional value, which is expressed by Qf.

(b)The effect of all the negative factors inside the object is called the dissipation value, which is expressed by Qh. [6]

(c)The value of use: the value of the function of things and the difference between the dissipation value is called the value of the thing, and Qu is expressed as this:

$\mathrm{Qu}=\mathrm{Qf}-\mathrm{Qh}$

where $\mathrm{Qf}=$ Functional value; $\mathrm{Qh}=$ the dissipation value; and $\mathrm{Qu}=$ The value of use.

The use value reflects the absolute impact of the essence of the object, which has been deducted from the negative effect of itself. Since dissipation value can be regarded as the functional value of negative values, so the use value can be regarded as the sum of the all positive values and negative values. It is easy to understand after decomposing the use value, why something has a very important function to the human survival and the development, but its using value is zero. For example, water, air, sunlight and other natural things are necessary for human survival and development, but human in the absorption and usage of it in need to be dissipated in another part of the function value, when the dissipation value of things is equal to the value function, its using value becomes zero. According to the use value of the marginal utility law, the function value of things with the subject of its rate of consumption growth and decline, when consumption growth rate is to a certain extent, the value of the function approaches to dissipation value, the use value of the things tend to zero.

So we get the resulting: use value zero theorems. To use value zero theorems: when things' supply rate or rate of consumption is large enough, the use value of the things tends to zero. And in our current our country, no matter public safety, or safety companies' supply speed is not very fast, but scarce. Therefore, safety of using value does not converge to zero. So safety is valuable. That is, the value of the function of safety is greater than the dissipation value, such as when the safety input (dissipation value) of every 1 Yuan, it can bring about 5 Yuan safety benefit (function value). In other words, the value of safety is positive $Q u=Q f-Q h>0$. 


\section{CONCLUSIONS}

This article analyzes the production of the safety is the unity of use value and value from two dimensions, namely Marxist Labor value dimension and the view of value and use value analyzing the safety philosophical reflection dimension. There are theoretical and practical significance for enterprises to improve further the safety of productive.

Changed the production enterprise is just a product or service concept in economics, The production of the enterprise has the duality, one is that the enterprise is the production safety of the system, namely through investment in safety that put human, financial, and material, to ensure that business is a safe system; the second is that the product or service enterprise production systems, through investment of the production, namely investment in human, financial, and material, to ensure that business is a the production or service product system. The second system can do its work only in the premise of the first system being effective. Sometimes the two are unified process, sometimes they need to be separated, but in the end they are unified.

Producers in the labor process, should get two benefits, one is safety benefits, namely through the production of their own safety or the safety of others (including enterprise safety investments), physically and mentally can be void to get harm from accident injuries, and second is to obtain remuneration in order to maintain their livelihood. Recognizing the safety has use value and value, in benefit of the handling of social conflicts and safety-related incidents, the safety value will be an important basis of safety investment.

\section{ACKNOWLEDGEMENTS}

This work was financially supported by the central university basic scientific research business expenses funded (No. 3142014014).

\section{REFERENCES}

[1] Shengpin Zou. The restrictions of Marxist labor theory of value [J]. Journal of guangxi university (philosophy and social sciences edition), 2006, 28 (5).

[2] Marx, Marx's theory of surplus value, the third volume, page 140.

[3] Marx and Engels. The complete works of Marx and Engels, 46 volume, page 104.

[4] Xianglan Chen, Xiaolu Wang. Correct understanding the constraint conditions of Marx's labor theory of value [J]. Journal of Hebei university of economy and trade, 2002, 23 (3).

[5] Marx, Marx's theory of surplus value, the third volume, page 7.

[6] Wencheng Lin. The added value of industrial product modeling development research [D]. Master of Chongqing university, 2009. 